\title{
Short-beam shear fatigue life assessment of thermally cycled carbon-aluminium laminates with protective glass interlayers
}

\author{
Barbara Surowska $^{1}$ iD $\cdot$ Konrad Dadej $^{1}$ iD $\cdot$ Patryk Jakubczak $^{1}$ (D) . Jarosław Bieniaś ${ }^{1}$ (D)
}

Received: 19 October 2020 / Revised: 4 January 2021 / Accepted: 8 January 2021 / Published online: 11 March 2021

(c) The Author(s) 2021

\begin{abstract}
Fibre metal laminates (FMLs) are attractive construction materials, especially for use in aerospace and transport facilities. Throughout their service life, thin-walled structures made of FMLs are exposed to static and dynamic loads, as well as corrosion and the unfavourable influence of environmental conditions. The paper presents an experimental analysis of the combined mechanical and environmental long-term behaviour of carbon-based fibre metal laminates and their variants with protective glass layers. The $\mathrm{Al}$ alloy/CFRP and $\mathrm{Al}$ alloy/GFRP/CFRP laminates in a $3 / 2$ configuration were used. The tested laminates were subjected to 1500 thermal cycles with a temperature range of $130{ }^{\circ} \mathrm{C}$. The static and fatigue interlaminar shear strengths were tested before and after thermal conditioning. It was shown that the stable stiffness reduction in the tested laminates was observed with increasing fatigue cycles, due to the progressive fatigue damage accumulation. The thermally cycled laminates feature slightly smoother stiffness loss, while a more rapid decrease was observed in thermally untreated laminates. Moreover, the fatigue life of the tested laminates subjected to thermal cycling revealed nine times fewer fatigue cycles of laminates with glass protectors after thermal cycles in comparison to the laminates not subjected to thermal cycling.
\end{abstract}

Keywords FML · GFRP · CFRP · Fatigue · ILSS · Thermal shock

\section{Introduction}

Fibre metal laminates (FMLs) are attractive construction materials, especially for use in aerospace and transport facilities. The first manufactured GLARE ${ }^{\circledR}$ and CARALL ${ }^{\circledR}$ laminates became the points of reference for developing the scientific basis for designing the properties of FMLs. Throughout their service life, thin-walled structures made of FMLs are exposed to static and dynamic loads, as well as corrosion and the unfavourable influence of environmental conditions. Due to this, in addition to typical mechanical tests, the process of designing primary and secondary structures must include corrosive, thermal and thermo-mechanical fatigue tests.

The properties of fibre metal laminates depend on those of the constitutive metal and composite materials. However, the final properties of an FML are influenced by a

Barbara Surowska

b.surowska@pollub.pl

1 Department of Materials Engineering, Faculty of Mechanical Engineering, Lublin University of Technology,

Nadbystrzycka 36, 20-618 Lublin, Poland large number of additional aspects. Besides the manufacturing technology, which may generate additional stresses in operating temperature, the adhesive joint between metal and composite serves a particularly important function. Insufficient critical strain energy release rate of the adhesive metal/ composite joint may result in the propagation of delamination, leading to the premature failure of the structures, e.g. when subjected to compression or fatigue. Generally, the mechanical properties of the adhesive joint may be traditionally evaluated by standard fracture toughness tests typically in the opening, shearing, or mixed shearing/opening mode. However, in recent years, short-beam shear (SBS) tests are also increasingly being used as mechanical tests, especially for comparative purposes. The previous example of using interlaminar shear strength (ILSS) to compare FML properties was presented by Sinmazçelik et al. [1] in a review paper from 2011. Kotik and Perez-Ipiña [2] employed the SBS test to obtain the information about quasi-static and fatigue interlaminar shear responses of a commercial FML. Liu et al. [3] showed that lay-up configuration of glass/epoxy layer strongly affected load-deflection response, especially the failure load, and corresponding failure mode. Bellini et al. [4] studied the influence of both composite/metal interface 
and layer thickness on ILSS in Al/CFRP laminates with extra polymer interlayers. They concluded that the most influencing factor was the presence of the structural adhesive, while the number of metal sheets was unaffecting.

As recently found, the adhesive connection of 2024-T3 aluminium alloy with glass fibres is in general characterized by a higher critical strain energy release rate than an adhesive connection with carbon fibres in both static [5] and fatigue [6] loadings, even though the same type of epoxy matrix is used. Nevertheless, the carbon-fibre-reinforced fibre metal laminates (CARALL type) are characterized by a significantly higher strength [7] and fatigue resistance [8], while having a lower density than glass-fibre-reinforced GLARE used in aircraft structures. However, the direct application of carbon fibres combined with an aluminium alloy in an aircraft structure is still considered to be risky due to the galvanic interaction between the aluminium alloy and carbon fibres. Liu et al. [9] and Peng et al. [10] confirmed the establishment of a galvanic couple and associated corrosion when the aluminium alloy is coupled to the CFRP composite. For this reason, in recent years, some attempts have been made to separate carbon fibres from an aluminium alloy by introducing additional dielectric layers as structural adhesive [4], prepreg resin [7], glass fibres [11] and glass fibres with adhesives [12], or other materials, such as rubber [13], also replacing an aluminium alloy with titanium [14].

It should be noted that even though the mechanical properties of hybrid carbon-fibre-reinforced laminates with added dielectric layers are rather promising, the long-term behaviour of those materials is investigated rather rarely. The influence of thermal cycling on the properties of GLARE with an external heating source was investigated by Müller et al. [15]. As the authors concluded, external heating and cooling as applied to GLARE, (with a temperature range of $120{ }^{\circ} \mathrm{C}$ ) increased their interlaminar shear strength by about $4 \%$ due to epoxy ageing. As a result, the aged matrix exhibited an increased stiffness and strength when compared to the reference material. Park et al. [16] noted a 9-18\% decrease of interlaminar shear strength of GLARE after 1500 thermal cycles. Khosravani and Weinberg [17] studied the influence of accelerated ageing on mechanical strength of GFRP/sandwich joint and observed the decrease of properties with adhesive failure. Garcia-Moreno et al. [18] studied the effect of thermal ageing on the impact damage resistance and tolerance of carbon-fibre-reinforced epoxy laminates. They concluded that thermal ageing below the glass transition temperature for short periods of time leads to a process called post-curing which consolidates the CFRP laminate improving the adhesion between the fibres and the matrix. On the other hand, Jakubczak et al. [19] found that the thermal cycling of CARALL laminates does not affect the value of interlaminar shear strength, although some differences in fractographical microstructural analyses were reported. Da
Costa et al. [20] also reported the limited influence of thermal cycles up to 2000 cycles of aluminium/glass laminates on shear strength.

Knowledge of the thermal and mechanical fatigue behaviour of components and hybrid laminates provides the ability to predict fatigue life and crack growth rates. The effects of cyclic loading on the fatigue of CFRP are detailed in several papers and collated in some review papers, e.g. by Alam et al. [21]. Zhou et al. [22] proposed the progressive fatigue damage modelling of fibre-reinforcedfibre-reinforced composite based on fatigue master curves. A method to predict the fatigue life and residual strength of composite materials subjected to variable amplitude loadings was proposed by D'Amore and Grassia [23]. Alderliesten [24], Homan [25] and others proposed analytical models of fatigue crack initiation and propagation in FMLs based on experimental results. Prediction methodologies for fatigue crack behaviour have been developed and verified for different loading [26, 27], different stress cycles and cycle characteristics [28], at various temperatures [29], etc. Therefore, when designing new hybrid laminates to operate under varying thermal and mechanical loads, it is necessary to expand the database of their properties as well as understanding the behavior under various load conditions (thermal, mechanical).

Taking assume above the aim of this paper was to analyse the combined mechanical and environmental long-term behaviour of carbon-based fibre metal laminates and their variants with protective glass layers. For this reason, laminates were subjected to 1500 thermal cycles with a temperature range of $130{ }^{\circ} \mathrm{C}$ (from -50 to $+80^{\circ} \mathrm{C}$ ), with subsequent mechanical fatigue loading until laminate failure. Through this, the combined environmental and mechanical long-term behaviour was investigated on CARALL with an additional dielectric glass fibre with two fibre orientations, and, for comparative purposes, on conventional carbon fibre-reinforced aluminium laminates.

\section{Materials and methods}

\subsection{Materials}

The studied laminates were GFRP and CFRP laminates containing layers of aluminium alloy. The thickness of aluminium alloy grade 2024-T3 sheets was $0.3 \mathrm{~mm}$. The surface of the sheets was coated with the organic-inorganic hybrid sol-gel 3 M Surface Pre-Treatment AC 130-2 two-component formulation (3 M, USA) as an adhesive film. See earlier publication for detailed information on the method of metal surface preparation and the used primer [12].

Carbon-fibre-reinforced epoxy prepreg (NTPT, Switzerland) with a fibre weight of $200 \mathrm{gsm}$ and a ply thickness of about $0.2 \mathrm{~mm}$ and ThinPly-type glass fibre/epoxy prepreg 
(NTPT, Switzerland) with a fibre weight of $40 \mathrm{gsm}$ and a layer thickness of $0.04 \mathrm{~mm}$ were laid in the $0^{\circ}$ and $90^{\circ}$ directions in sequences, as shown in Fig. 1. Sample notation is presented in Table 1. When an ultra-thin glass layer is laminated in the $0^{\circ}$ direction, i.e. in accordance with the direction of carbon fibres, local contact of carbon fibres with aluminium may occur due to the migration of fibres during the autoclave process [19]. Therefore, a perpendicular GFRP layer was also used as an effective barrier to avoid carbon and glass fibre interpenetration, while the GFRP layers were laminated in a perpendicular direction. CARALL in a $3 / 2$ configuration was used as the reference material.

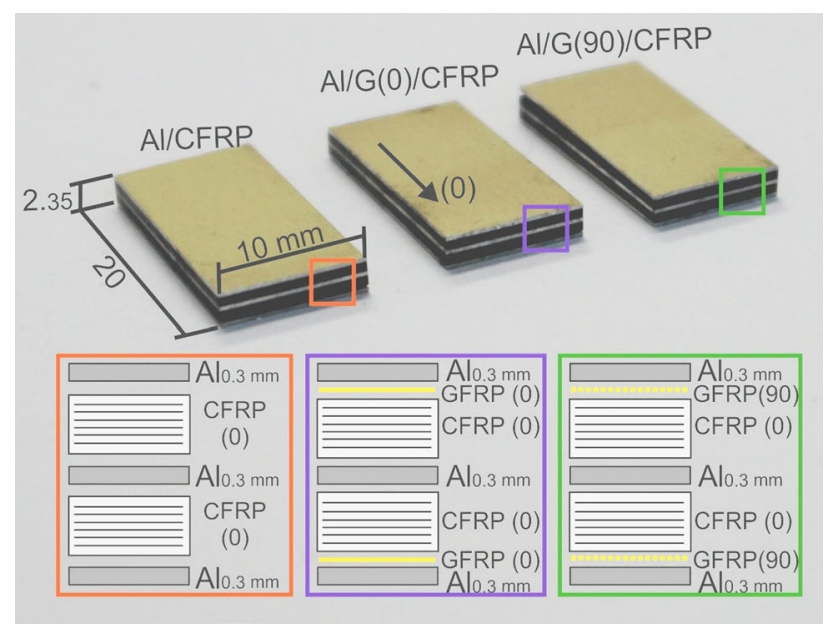

Fig. 1 The configurations of the tested laminates
The panels were manufactured using the autoclave method with vacuum bag assistance (SCHOLZ Maschinenbau autoclave, Germany). The curing involved a two-step temperature process $\left(80^{\circ} \mathrm{C}\right.$ for $1 \mathrm{~h}$ and $150{ }^{\circ} \mathrm{C}$ for $4 \mathrm{~h}$ ). The heating and cooling rates were $1.2{ }^{\circ} \mathrm{C} / \mathrm{min}$. The pressure was $0.6 \mathrm{MPa}$ and the vacuum was $0.02 \mathrm{MPa}$ throughout the process.

The panels were cut into short-beam shear (SBS) samples using a water jet. The average sample size was $20 \times 10 \times 2.35 \mathrm{~mm}$.

\subsection{Methods}

To assess the influence of glass layer configuration on mechanical properties under variable load conditions, a test methodology was developed, including thermal shocks and cyclic bending load.

Thermal shocks were carried out in an environmental chamber (Binder MKFT type, Germany) according to the scheme shown in Table 2 and in Fig. 2a. The samples in the environmental chamber are shown in Fig. 2b. The temperature was changed from -50 to $+80^{\circ} \mathrm{C}$. In general, this range of temperature is typical in aircraft operating. Used thermal conditions can be compared to real conditions for aircraft structures, e.g. fuselage during standard operation (ascents and descents $-55^{\circ} \mathrm{C}$ to $+70{ }^{\circ} \mathrm{C}$, also anti- or deicing $-25{ }^{\circ} \mathrm{C}$ to $\left.+80{ }^{\circ} \mathrm{C}\right)[15,18,20]$. The detailed course of this research is described in other works [12, 19].

Strength tests were performed as quasi-static and fatigue tests before and after thermal shocks. The short-beam sample

Table 1 Notation of samples

\begin{tabular}{|c|c|c|}
\hline Notation & Conditions & Sample configuration \\
\hline \multicolumn{3}{|l|}{ Al/CFRP } \\
\hline $\mathrm{NC}$ & No shocks & $\mathrm{Al} / \mathrm{CFRP}(0)_{4} / \mathrm{Al} / \mathrm{CFRP}(0)_{4} / \mathrm{Al}($ Carall 3/2) \\
\hline $\mathrm{SC}$ & After shocks & \\
\hline \multicolumn{3}{|l|}{$\mathrm{Al} / \mathrm{G}(0) / \mathrm{CFRP}$} \\
\hline NG0C & No shocks & $\mathrm{Al} / \mathrm{GFRP}(0) / \mathrm{CFRP}(0)_{4} / \mathrm{Al} / \mathrm{CFRP}(0)_{4} / \mathrm{GFRP}(0) / \mathrm{Al}$ \\
\hline SG0C & After shocks & \\
\hline \multicolumn{3}{|l|}{$\mathrm{Al} / \mathrm{G}(90) / \mathrm{CFRP}$} \\
\hline NG90C & No shocks & $\mathrm{Al} / \mathrm{GFRP}(90) / \mathrm{CFRP}(0)_{4} / \mathrm{Al} / \mathrm{CFRP}(0)_{4} / \mathrm{GFRP}(90) / \mathrm{Al}$ \\
\hline SG90C & After shocks & \\
\hline \multicolumn{3}{|c|}{ Mechanical properties of tested Al/CFRP laminate* and two other types** } \\
\hline \multicolumn{3}{|l|}{ Tensile strength: $1207 \mathrm{MPa} \pm 99$ (ASTM D3039) } \\
\hline \multicolumn{3}{|l|}{ Young modulus: $94 \mathrm{GPa} \pm 3$ (ASTM D3039) } \\
\hline \multicolumn{3}{|l|}{ Poisson ratio: $0.28 \pm 0.01$ (ASTM D3039) } \\
\hline Compressive strength: $834 \mathrm{MPa} \pm 6$ (ASTM 3410) & & \\
\hline
\end{tabular}


Table 2 Parameters of thermal cycles

\begin{tabular}{lllll}
\hline Cycle no & Cycle name & Time (min) & $\begin{array}{l}\text { Temperature } \\
\left({ }^{\circ} \mathrm{C}\right)\end{array}$ & $\begin{array}{l}\text { Heating/ } \\
\text { cooling rate } \\
\left({ }^{\circ} \mathrm{C} / \mathrm{min}\right)\end{array}$ \\
\hline 0 & Start & 14.2 & $\mathrm{RT}^{\mathrm{a}} \rightarrow-50$ & 5 \\
1 & Stabilization & 5 & -50 & - \\
& Heating & 26 & $-50 \rightarrow 80$ & 5 \\
& Stabilization & 5 & 80 & - \\
2 & Cooling & 26 & $80 \rightarrow-50$ & 5 \\
& Stabilization & 5 & -50 & - \\
& Heating & 26 & $-50 \rightarrow 80$ & 5 \\
& Stabilization & 5 & 80 & - \\
etc. until & Cooling & 26 & $80 \rightarrow-50$ & 5 \\
1500 & Stabilization & 5 & -50 & - \\
& Heating & 26 & $-50 \rightarrow 80$ & 5 \\
& Stabilization & 5 & 80 & - \\
& Cooling & 26 & $80 \rightarrow-50$ & 5 \\
& Stop & 14.2 & $-50 \rightarrow \mathrm{RT}$ & 5 \\
\hline
\end{tabular}

${ }^{\text {a }}$ Room temperature $21^{\circ} \mathrm{C}$

bending method according to the EN ISO 14130:1997 standard was used [30]. Interlaminar shear strength (ILSS) was determined using the following equation [30]:

$\tau=\frac{3}{4} \frac{P}{b h}[\mathrm{MPa}]$,

where $P$ is the maximum load [N], and $b$ and $h$ are the width and thickness of the specimen [mm], respectively.

A three-point bending device was used. The radii of support rollers and the loading member were $2 \mathrm{~mm}$ and $5 \mathrm{~mm}$, respectively. A span-to-thickness ratio of 5.0 was used. The quasi-static tests were performed on a Shimadzu AG-X Plus mechanical testing machine (Japan) with the crosshead speed of $1.3 \mathrm{~mm} / \mathrm{min}$.

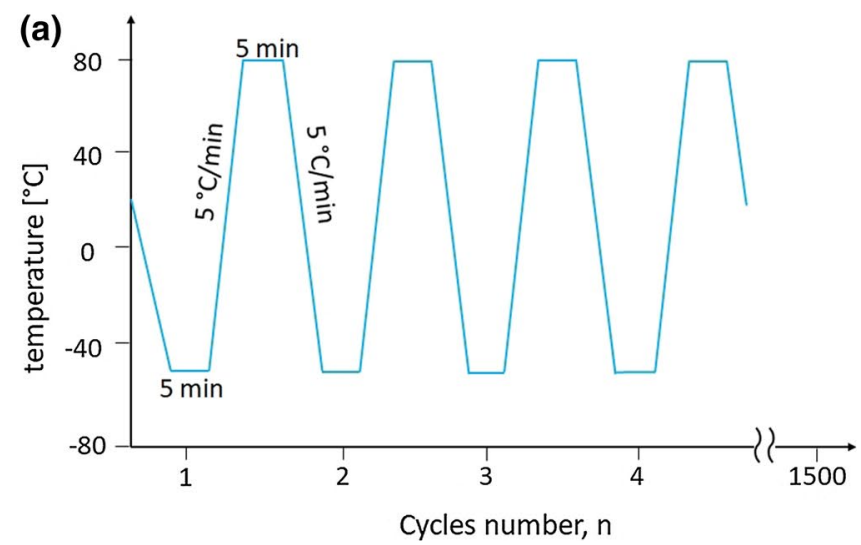

The fatigue tests were performed using the INSTRON 8801 Fatigue Testing Systems $100 \mathrm{kN}$ (UK) machine with an additional load cell INTERFACE 1010ACK-5KN-B (USA) with a $5 \mathrm{kN}$ load capacity. The specimens were force-driven tested at a $5 \mathrm{~Hz}$ loading frequency. The maximum load level in fatigue tests was specified as $65 \%$ of the static ILSS. According to Kotik and Perez-Ipina [2] this loading range is recommended to obtain stable progressive fatigue damage of the short-beam shear specimen and, as a result, a stable stiffness decrease until the final failure. Fatigue tests were conducted until the stiffness of the specimen degraded below $20 \%$ of its initial value $\left(S_{\text {ini }}\right)$. Ten and three specimens for each configuration were tested in quasi-static and dynamic bending tests, respectively. The scheme and the real view of the ILSS test are presented in Fig. 3, while the test procedure is presented in Fig. 4.

\section{Results and discussion}

\subsection{Static interlaminar shear}

The static bending test was carried out to determine the maximum shear stress of laminates before and after thermal shocks. The stress values were necessary to establish fatigue test parameters.

Table 3 and Fig. 5 contain the averaged test results. Laminates containing a layer of glass fibre showed a slight tendency to ILSS decrease due to thermal shocks. The CARALL type laminate showed an increase in stress after 1500 thermal cycles.

Although there is a slight tendency to ILSS change, statistical analysis with the HSD Tukey test did not show statistically significant differences between the calculated ILSS values (see Table 4), with the exception of SC samples.

Similar trends have been observed in authors previous studies for laminates with a different method of aluminium

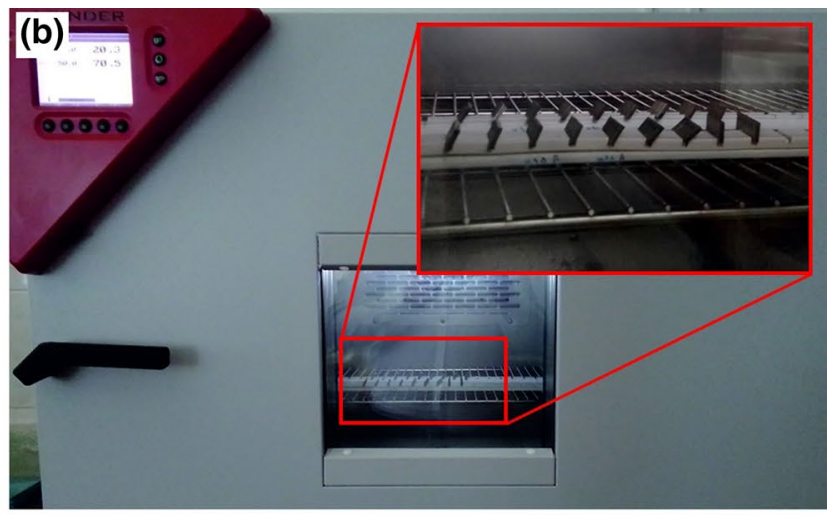

Fig. 2 Scheme of thermal cycles (a) and the samples inside the environmental chamber (b) 
(a)

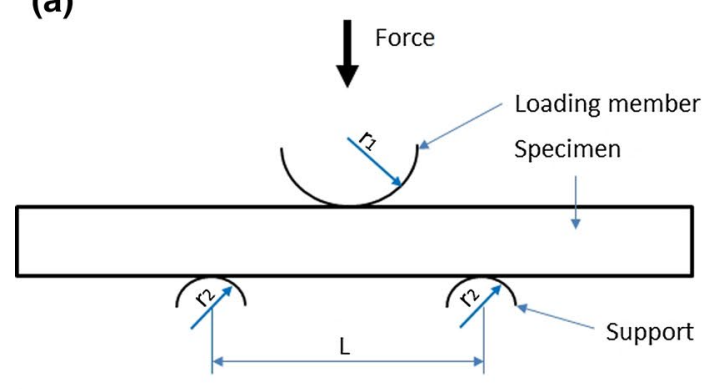

$\mathrm{L}$-span: $10 \mathrm{~mm}$

$r_{1}$ - radius of loading member: $5 \mathrm{~mm}$

$r_{2}-$ radius of support: $2 \mathrm{~mm}$

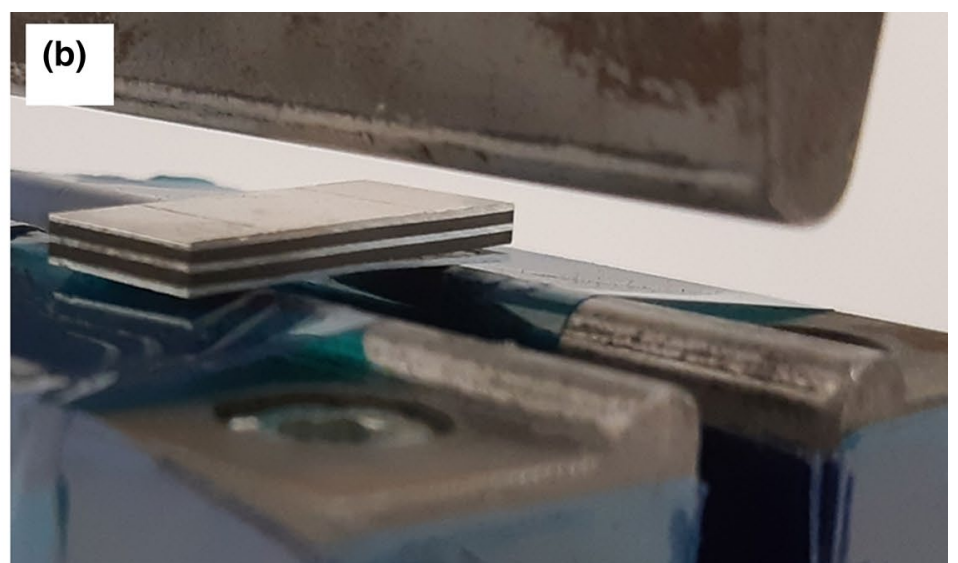

Fig. 3 The scheme (a) and sample view (b) of ILSS static and fatigue tests

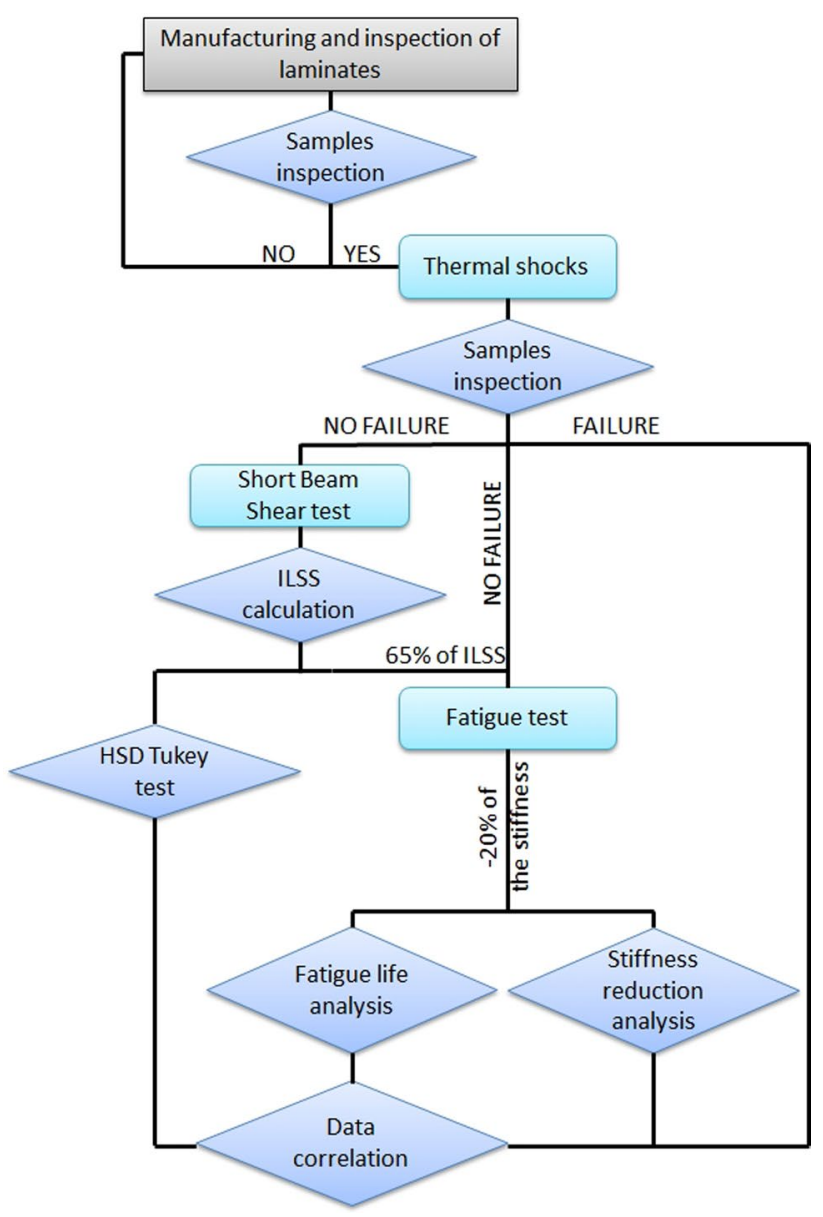

Fig. 4 The scheme of the full test procedure

surface preparation $[12,19]$ and in hygrothermal conditions by da Costa [20]. Significant effects of thermal shocks on GLARE [15, 31-33] and CARALL [34, 35] laminates were only observed after more than 10,000 thermal cycles. The lack of significant difference in interlaminar shear strength of the tested laminates results from the very low thickness of glass layers and effectively limiting degradation of the metal/composite interface. It is known that the interlaminar shear strength of FML is controlled by the interface between the metal and the composite layer [20,35]. Stresses resulting from thermal shocks generally reach the maximum value at the fibre-matrix interfaces and boundaries between adjacent composite layers of different fibre orientations [35]. Moreover, the epoxy matrix may become plasticized or swell, reducing ILSS [36, 37]. In good metal/composite interfacial adhesion systems, these effects are not significant. The used organic-inorganic hybrid sol-gel primer belonging to the second-generation coatings ensures a high corrosion resistance by creating a dense $-\mathrm{Si}-\mathrm{O}-\mathrm{Si}-$ network and providing high adhesion to metal surfaces, owing to the formation of covalent Me-O-Si bonds [38, 39]. The observed increase of ILSS in Al/CFRP and the constant value of ILSS in Al/G/ CFRP after thermal shocks are probably due to the reaction between the metal, epoxy and primer, leading to an increase in bond strength in the interface area [40]. It should be also noted, that the formula used for the determination of ILSS is based on homogeneous beam theory, which predicts a continuous, parabolic distribution of the shear stress, with a maximum on the neutral plane of the laminated beams [41]. In the current specimens, the above-mentioned formula yields the maximum stress value, which occurs in the middle of the aluminium layer. Despite in the literature, more advanced mechanical models can be found [41], for instance, Classical Sandwich Theory, for the comparisons of the interface durability before and after any processing, the primary formula, Eq. (1) yields reasonable results [2, 3, 5, 7, 41, 42]. It is also worth mentioning that, the investigated metal/composite interfaces are placed with a very slight offset from the neutral plane of $0.15 \mathrm{~mm}$, meaning that the real ILSS value could be insignificantly lower than measured. However, as 
Table 3 Interlaminar shear strength of laminates before and after thermal shocks

\begin{tabular}{llllll}
\hline Sample & $P_{\max }(\mathrm{N})$ & ILSS $(\mathrm{MPa})$ & Sample & $P_{\max }(\mathrm{N})$ & ILSS (MPa) \\
\hline NC & $2033 \pm 102$ & $70.33 \pm 3.24$ & SC & $2353 \pm 111$ & $76.79 \pm 3.32$ \\
& $\mathrm{CV}=5.0$ & $\mathrm{CV}=4.6$ & & $\mathrm{CV}=4.7$ & $\mathrm{CV}=4.32$ \\
NG0C & $2243 \pm 119$ & $71.18 \pm 3.1$ & SG0C & $2115 \pm 110$ & $68.31 \pm 3.29$ \\
& $\mathrm{CV}=5.3$ & $\mathrm{CV}=4.35$ & & $\mathrm{CV}=5.2$ & $\mathrm{CV}=4.82$ \\
NG90C & $2270 \pm 82$ & $72,65 \pm 2.06$ & SG90C & $2155 \pm 93$ & $68.52 \pm 2.9$ \\
& $\mathrm{CV}=3.6$ & $\mathrm{CV}=2.83$ & & $\mathrm{CV}=4.3$ & $\mathrm{CV}=4.29$ \\
\hline
\end{tabular}

$C V$ sample coefficient of variation, in percent

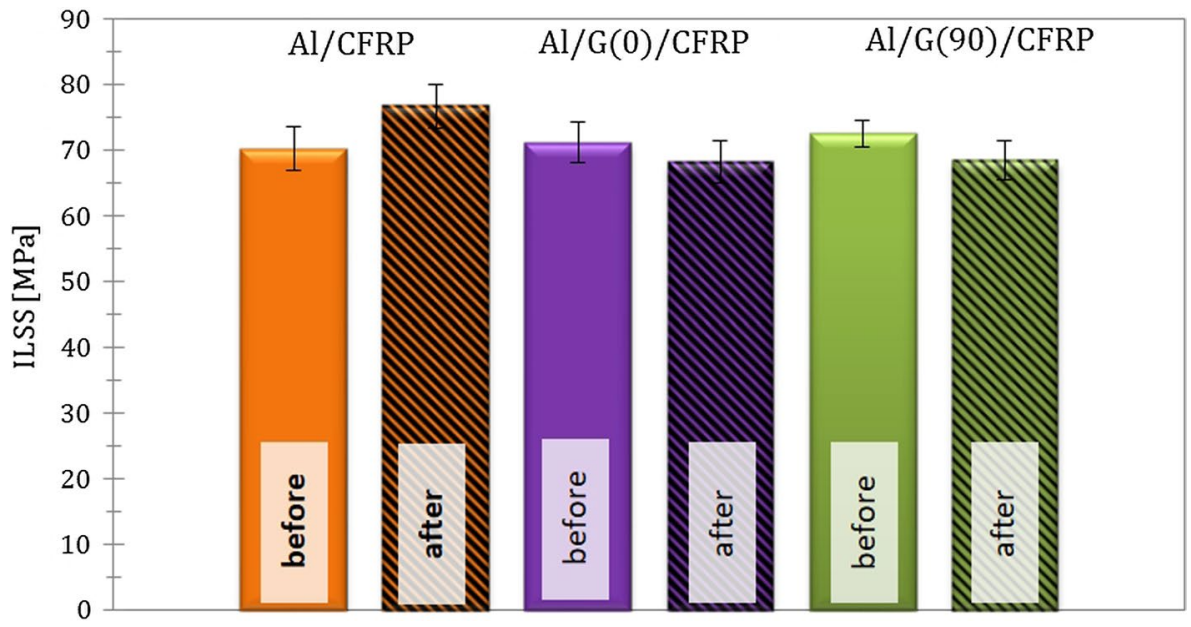

\begin{tabular}{lllllll}
\hline & $70.33\{1\}$ & $71.18\{2\}$ & $72.65\{3\}$ & $76.79\{4\}$ & $68.31\{5\}$ & $68.52\{6\}$ \\
\hline NC $\{1\}$ & & 0.991 & 0.585 & 0.001 & 0.714 & 0.796 \\
NG0C $\{2\}$ & 0.991 & & 0.905 & 0.003 & 0.348 & 0.430 \\
NG90C $\{3\}$ & 0.585 & 0.905 & & 0.055 & 0.040 & 0.057 \\
SC $\{4\}$ & 0.001 & 0.003 & 0.055 & & 0.000 & 0.000 \\
SG0C $\{5\}$ & 0.714 & 0.348 & 0.040 & 0.000 & & 1.000 \\
SG90C $\{6\}$ & 0.796 & 0.430 & 0.057 & 0.000 & 1.000 & \\
\hline
\end{tabular}

Fig. 5 Interlaminar shear strength of laminates before and after thermal shocks
Table 4 Result of HSD Tukey test for ILSS
Table 3) the fatigue test after environmental conditioning was performed at constant stress levels for the global specimen population. However, due to the differences of specimen thickness, caused by the different layups, the maximum forces were adjusted to each specimen to obtain constant interlaminar shear stress (46.3 MPa) regardless of the layup configuration. The geometry and resulting force levels as well as the $S_{\text {ini }}$ initial stiffness value (determined after 100 fatigue cycles) are specified in Table 5 .

Fatigue tests were performed until the stiffness decreased below $20 \%$ of their initial value. The fatigue test results for reference materials before thermal shocks and after thermal shocks are shown in Fig. 6.

As can be seen in Fig. 6, in the first stage of mechanical fatigue life (from 1 to 103 cycles), the material's cyclic hardening was observed. The normalized laminate stiffness $\left(S_{i} /\right.$ $S_{\text {ini }}$ ) increased up to $10 \%$ for all of the tested specimens. A 
Table 5 SBS fatigue test parameters

\begin{tabular}{|c|c|c|c|c|c|c|c|c|c|}
\hline$h(\mathrm{~mm})$ & $b(\mathrm{~mm})$ & $\tau_{\max (65 \%)}(\mathrm{MPa})$ & $P_{\max }(\mathrm{N})$ & $P_{\text {min }}(\mathrm{N})$ & $\Delta P(\mathrm{~N})$ & $\delta$ at $P_{\max }(\mathrm{mm})$ & $\delta$ at $P_{\min }(\mathrm{mm})$ & $\Delta \delta(\mathrm{mm})$ & $\begin{array}{l}S_{\text {ini }} \Delta P / \Delta \delta \\
(\mathrm{N} / \mathrm{mm})\end{array}$ \\
\hline \multicolumn{10}{|l|}{$\mathrm{NC}$} \\
\hline 2.32 & 9.93 & 46.3 & 1423 & 142 & 1281 & 27.501 & 27.407 & 0.0936 & 13,692 \\
\hline 2.29 & 9.88 & 46.3 & 1398 & 140 & 1258 & 27.504 & 27.414 & 0.0891 & 14,125 \\
\hline 2.32 & 9.93 & 46.3 & 1420 & 142 & 1278 & 27.512 & 27.425 & 0.0870 & 14,691 \\
\hline \multicolumn{10}{|l|}{ NG0C } \\
\hline 2.37 & 9.88 & 46.3 & 1443 & 144 & 1299 & 27.681 & 27.591 & 0.0902 & 14,397 \\
\hline 2.35 & 9.89 & 46.3 & 1435 & 144 & 1292 & 27.594 & 27.508 & 0.0864 & 14,946 \\
\hline 2.37 & 9.88 & 46.3 & 1444 & 144 & 1299 & 27.572 & 27.487 & 0.0852 & 15,243 \\
\hline \multicolumn{10}{|l|}{ NG90C } \\
\hline 2.42 & 9.93 & 46.3 & 1482 & 148 & 1333 & 27.490 & 27.398 & 0.0916 & 14,561 \\
\hline 2.38 & 9.88 & 46.3 & 1452 & 145 & 1307 & 27.568 & 27.485 & 0.0832 & 15,709 \\
\hline 2.39 & 9.94 & 46.3 & 1464 & 146 & 1318 & 27.557 & 27.467 & 0.0897 & 14,697 \\
\hline \multicolumn{10}{|l|}{$\mathrm{SC}$} \\
\hline 2.34 & 9.90 & 46.3 & 1428 & 143 & 1285 & 27.602 & 27.511 & 0.0910 & 14,130 \\
\hline 2.36 & 9.94 & 46.3 & 1449 & 145 & 1304 & 27.584 & 27.502 & 0.0819 & 15,931 \\
\hline 2.35 & 9.92 & 46.3 & 1440 & 144 & 1296 & 27.603 & 27.510 & 0.0925 & 14,001 \\
\hline \multicolumn{10}{|l|}{ SG0C } \\
\hline 2.45 & 9.90 & 46.3 & 1499 & 150 & 1349 & 27.493 & 27.399 & 0.0945 & 14,276 \\
\hline 2.45 & 9.92 & 46.3 & 1501 & 150 & 1351 & 27.508 & 27.419 & 0.0892 & 15,145 \\
\hline 2.41 & 9.92 & 46.3 & 1476 & 148 & 1329 & 27.616 & 27.507 & 0.1093 & 12,162 \\
\hline \multicolumn{10}{|l|}{ SG90C } \\
\hline 2.41 & 9.94 & 46.3 & 1477 & 148 & 1329 & 27.579 & 27.491 & 0.0887 & 14,982 \\
\hline 2.40 & 9.95 & 46.3 & 1475 & 148 & 1328 & 27.609 & 27.487 & 0.1220 & 10,883 \\
\hline 2.41 & 9.94 & 46.3 & 1480 & 148 & 1332 & 27.528 & 27.431 & 0.0972 & 13,700 \\
\hline
\end{tabular}

similar increase of the specimen stiffness of the short-beam shear specimens could be explained by the cyclic strain hardening of the 2024-T3 aluminium alloy. As described by Calabrese and Laird [43], the accumulation of dislocations, as well as their interaction with precipitations in two-phase alloys (in this case $4 \%$ copper and $1 \%$ magnesium were alloying elements), may significantly increase material stiffness subjected to cycling loading. After initial stiffness gain, a stable stiffness reduction was observed in tested laminates, due to the progressive fatigue damage accumulation. In the last phase of the specimens' fatigue life, a sudden stiffness drop was observed in every tested layup. An analysis of the stiffness history of thermally cycled laminates with reference materials demonstrates that thermally cycled laminates seem to be characterized by a slightly smoother stiffness loss, while a more rapid decrease was observed in thermally untreated laminates. The initial stiffness of the specimens subjected to thermal cycling and of the reference materials is specified in Table 6 .

Comparing resistance to thermo-mechanical fatigue, as a function of the layup configurations, it may be observed that the thermal cycling caused a slight decrease of specimen stiffness in laminates with additional glass fibres in both $0^{\circ}$ and $90^{\circ}$ fibre orientations $(-7 \%$ and $-12 \%$ respectively), while some additional hardening was observed in the laminate reinforced only by carbon fibres $(+4 \%)$. A similar increase $(+4 \%)$ of ILLS was observed by Müller et al. [15] in static SBS tests performed on GLARE. Müller et al. [15] explain this effect by the ageing of epoxy, which increases its stiffness and, as a result, also leads to the strengthening of the fibre metal laminate. Similarly, Li et al. [32] observed an increase in the static tensile and bending strength of the FMLs after thermal fatigue cycling due to the advantageous ageing behaviour and the resulting hardening of the aluminium-lithium layer. Kubit et al. [44] observed a decrease in stiffness and ILSS after the thermal cycling of fibre metal laminate made of prepregs with twisted yarn and aluminium alloy 2024-T3. Also, Hagenbeek et al. [31] observed a significant (in the range of 10-30\%) decrease of ILSS after long-term thermal cycling of a fibre metal laminate reinforced by glass fibres. In the current research, also a similar significant decrease of stiffness and static ILSS (in the range of $7-12 \%$ ) was observed in laminates with additional layers of glass fibres. On the other hand, Costa et al. [20] evaluated the effect of thermal-shock cycles (max. 2000 cycles) with temperature variations between -50 and $+80{ }^{\circ} \mathrm{C}$ on 
Fig. 6 Stiffness vs. fatigue cycles before (a) and after (b) thermal shocks
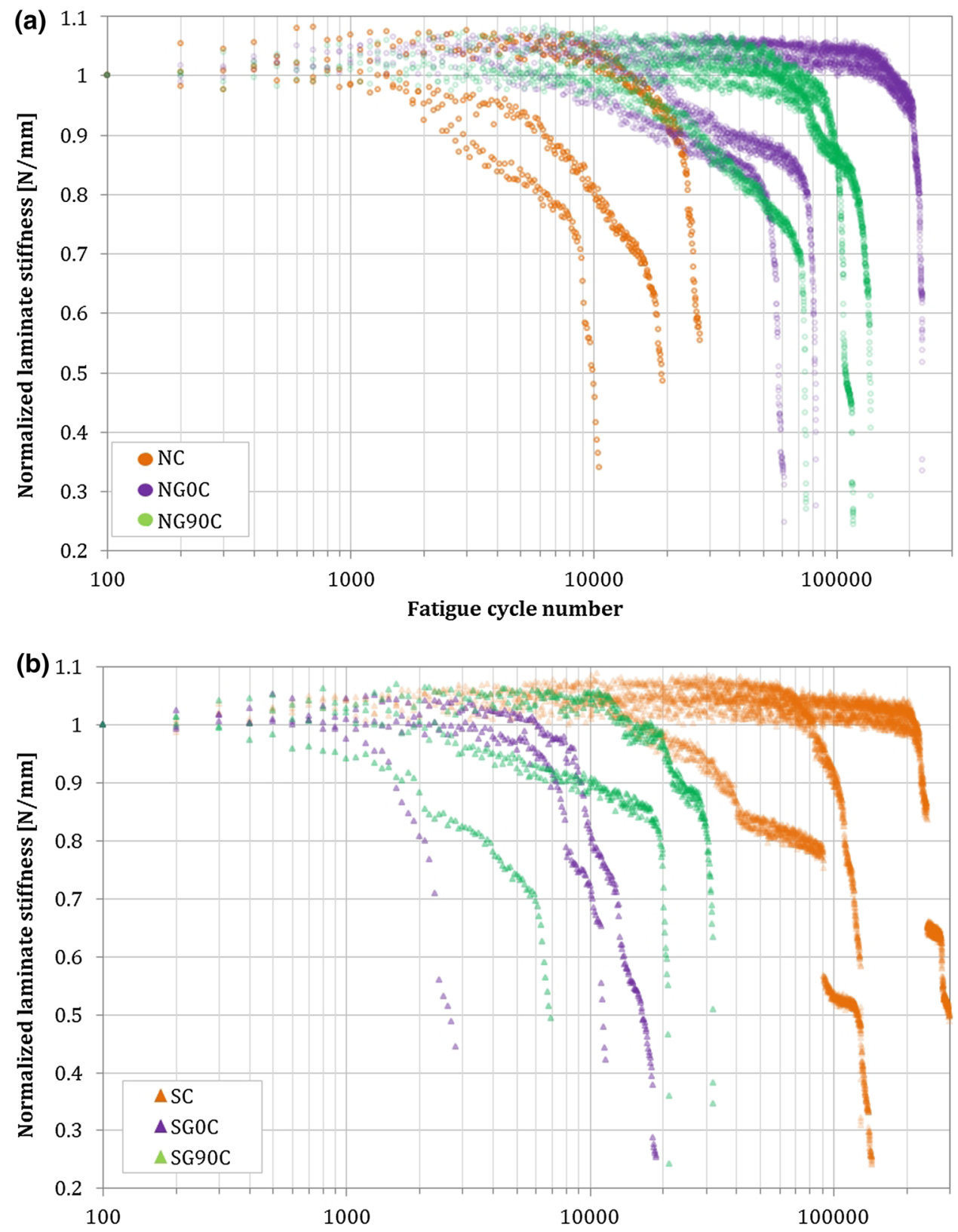

Fatigue cycle number the mechanical properties of Al/GFRP/epoxy adhesive tape laminates and observed that the thermal-shock cycles did not result in significant microstructural changes and interlaminar shear strength of the FML.

In analyzing the fatigue life of the tested materials (fatigue number up to final failure or $80 \%$ stiffness loss), also in this case significant strengthening was observed in laminates reinforced only by carbon fibres. Although the stiffness of laminates increased rather slightly, the fatigue life of the corresponding laminate subjected to thermal cycling (material SC) withstood almost nine times more fatigue cycles than the reference materials (material NC).
The carbon-fibre-reinforced FMLs, which after thermal shocks had the highest ILSS, were subjected to relatively lower fatigue loads than the other layups. This may be the reason for the higher SBS fatigue life obtained. However, maintaining specified stress at a constant level for both thermally cycled and reference specimens is rational, since the loads applied under the real loading conditions do not decrease in the operating conditions (e.g. in the aircraft industry), but remain at a constant, designed level. Although an increase in fatigue strength was observed for laminates reinforced only with carbon fibres, the thermal cycling of fibre metal laminates reinforced by mixed carbon and glass 
Table 6 Initial stiffness of short-beam shear specimens before and after thermal shocks

\begin{tabular}{llllll}
\hline \multicolumn{6}{l}{ Initial stiffness $\left(S_{\text {ini }}\right) \Delta P / \Delta \delta(\mathrm{N} / \mathrm{mm})$} \\
\hline \multicolumn{7}{c}{1} & 2 & 3 & Mean & Change \\
\hline \multicolumn{2}{l}{ Before thermal shocks } \\
NC & 13,692 & 14,125 & 14,691 & 14,169 & Reference \\
NG0C & 14,397 & 14,946 & 15,243 & 14,862 & Reference \\
NG90C & 14,561 & 15,709 & 14,697 & 14,989 & Reference \\
After 1500 thermal shocks & & & \\
SC & 14,130 & 15,931 & 14,001 & 14,687 & + \\
SG0C & 14,276 & 15,145 & 12,162 & 13,861 & - \\
SG90C & 14,982 & 10,883 & 13,700 & 13,188 & - \\
\hline
\end{tabular}

Table 7 Fatigue life of short-beam shear specimens before and after thermal shocks

\begin{tabular}{lrrrrl}
\hline \multicolumn{7}{l}{ Fatigue cycles (cycles) } \\
\hline \multicolumn{2}{c}{1} & \multicolumn{3}{l}{$l$} \\
\hline Before thermal shocks & & Geometric mean & Change \\
NC & 28,900 & 19,100 & 9900 & 17,614 & Reference \\
NG0C & 82,000 & 226,800 & 57,800 & 102,438 & Reference \\
NG90C & 108,900 & 137,800 & 74,300 & 103,694 & Reference \\
After 1500 thermal shocks & & & \\
SC & 125,200 & 297,100 & 129,400 & 168,842 & + \\
SG0C & 11,400 & 16,400 & 2700 & 7962 & - \\
SG90C & 21,000 & 6900 & 32,000 & 16,675 & - \\
\hline
\end{tabular}

fibres (regardless of fibre orientation) caused heavy deterioration of their fatigue life. The results for fatigue life are presented in Table 7 and Fig. 7.

A similar number of fatigue cycles to failure $(22,000$ fatigue cycles - geometrical average) of non-thermally cycled fibre metal laminates were observed by Kotik and Perez-Ipina [2] in GLARE loaded by a shear stress amplitude with a magnitude of 23.4 MPa. For the specified stress levels, the authors observed stable and repetitive fracture mechanisms, where the cracks formed in the middle of the span in the bottom aluminium layer. Although the order of magnitude of fatigue cycles is similar to Kotik and PerezIpina [2] results, some dispersion of the obtained fatigue life results have been observed. A possible origin of the dispersion of results for different tested layup configurations is the existence of differences in laminate thickness. Although the thickness differences in tested laminates were very slight (thickness, $t$, Table 5), Liu et al. [3] showed that the span-to-thickness ratio in an SBS test based on a threepoint-bending test is crucial for the resulting ILSS value, by changing failure mode from shear-dominant for a low span-to-thickness ratio (about $s / t=5$ ) to bending-dominant for a high span-to-thickness ratio $(s / t=10)$. Therefore, at the span remaining at a constant level, $(s=10 \mathrm{~mm})$ even minor differences in laminate thickness would change the span-tothickness ratio and the resulting loading mode. The application of extra glass layers affects laminate thickness, but also the Young modulus mismatch, which are important factors for stiffness changes and final fatigue strength. The aspects of the thermal expansion coefficient of aluminium, carbon and extra glass layers could be an extra factor for different long-term thermal-mechanical behaviour. However, in the case of fibre metal laminates cured under high temperature (up to $180{ }^{\circ} \mathrm{C}$ ) curing conditions the manufacturing stresses also can influence the initial stress-state of a laminate [45] despite the presence of protective glass layers. For this reason, the simple modification of an anti-corrosive barrier via thin glass fibres cannot be considered as critical for thermal shock resistance.

\section{Summary}

This paper presents an experimental analysis of the mixed mechanical-environmental long-term behaviour of carbonbased fibre metal laminates and their variations with glass
Fig. 7 The influence of thermal shocks on the fatigue life of SBS specimens

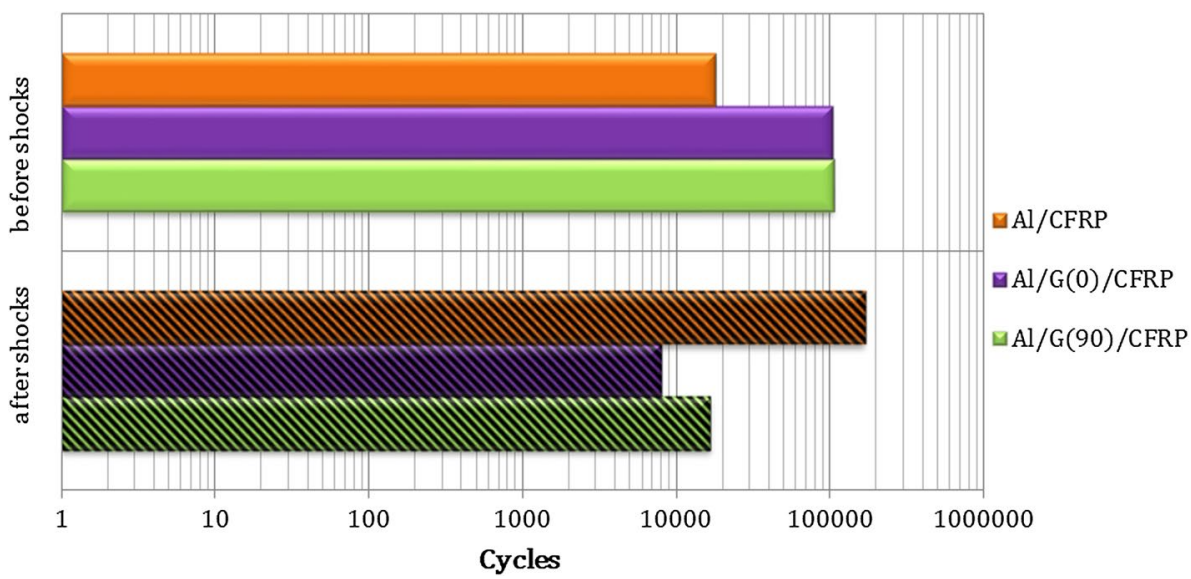


protective layers. The laminates were subjected to 1500 thermal cycles with a temperature range of $130{ }^{\circ} \mathrm{C}$. The static and fatigue interlaminar shear strengths were tested before and after thermal conditioning. The fatigue life as well as laminate stiffness changes were analysed and compared in terms of the thermal conditioning effect. Based on the conducted research it was demonstrated that although there was a slight tendency to ILSS change after thermal shocks, statistical analysis did not show statistically significant differences between the ILSS values.

Based on results some conclusions were noted:

- the static interlaminar shear strength does not depend on thermal cycles or on the thin glass protective films applied between the metal and carbon layers.

- the fatigue response of carbon-based FMLs (and their variations with glass protective layers) is characterized by some visible thermal cycle dependence. The stable stiffness reduction in the tested laminates was observed with increasing fatigue cycles, due to the progressive fatigue damage accumulation. The thermally cycled laminates feature slightly smoother stiffness loss, while a more rapid decrease was observed in thermally untreated laminates. An additional factor of the laminate stiffness reduction after thermal cycling is the presence of additional glass fibres in both the $0^{\circ}$ and $90^{\circ}$ fibre orientations.

- an analysis of the fatigue life of the tested laminates subjected to thermal cycling revealed nine times fewer fatigue cycles of laminates with glass protectors after thermal cycles in comparison to the reference materials (laminates not subjected to thermal cycling).

- the mechanical long-term behaviour of carbon-based fibre metal laminates and their variants with glass protective layers is adversely affected by the earlier thermal-cyclic conditions. The main factor in that is the fact of Young modulus change and mismatch through laminate thickness with a simultaneous strength reduction of metal/composite interfaces due to thermal expansion effects.

Acknowledgements The project/research was financed within the framework of the project Lublin University of Technology-Regional Excellence Initiative, funded by the Polish Ministry of Science and Higher Education (contract no. 030/RID/2018/19).

Funding Polish Ministry of Science and Higher Education (Contract no. 030/RID/2018/19).

Availability of data and material The raw/processed data required to reproduce these findings can be shared via request.

\section{Compliance with ethical standards}

Conflict of interest The authors declare that they have no known competing financial interests or personal relationships that could have appeared to influence the work reported in this paper.

Open Access This article is licensed under a Creative Commons Attribution 4.0 International License, which permits use, sharing, adaptation, distribution and reproduction in any medium or format, as long as you give appropriate credit to the original author(s) and the source, provide a link to the Creative Commons licence, and indicate if changes were made. The images or other third party material in this article are included in the article's Creative Commons licence, unless indicated otherwise in a credit line to the material. If material is not included in the article's Creative Commons licence and your intended use is not permitted by statutory regulation or exceeds the permitted use, you will need to obtain permission directly from the copyright holder. To view a copy of this licence, visit http://creativecommons.org/licenses/by/4.0/.

\section{References}

1. Sinmazçelik T, Avcu E, Bora MO, Çoban O. A review: fibre metal laminates, background, bonding types and applied test methods. Mater Des. 2011;32:3671-85.

2. Kotik HG, Perez-Ipiña JE. Short-beam shear fatigue behavior of fiber metal laminate (Glare). Int J Fatigue. 2017;95:236-42.

3. Liu C, Du D, Li H, Hu Y, Xu Y, Tian J, Tao G, Tao J. Interlaminar failure behavior of GLARE laminates under short-beam threepoint-bending load. Compos Part B. 2016;97:361-7.

4. Bellini C, Di Cocco V, Iacoviello F, Sorrentino L. Influence of structural characteristics on the interlaminar shear strength of CFRP/Al fibre metal laminates. Procedia Struct Integr. 2019;18:373-8.

5. Bellini C, Di Cocco V, Iacoviello F, Sorrentino L. Performance evaluation of CFRP/Al fibre metal laminates with different structural characteristics. Compos Struct. 2019;225:111-7.

6. Bienias J, Dadej K. Fatigue delamination growth of carbon and glass reinforced fiber metal laminates in fracture mode II. Int $\mathrm{J}$ Fatigue. 2020;130:105267.

7. Bellini C, Di Cocco V, Iacoviello F, Sorrentino L. Analysis of CFRP/Al hybrid laminates flexural strength. Procedia Struct Integr. 2019;18:368-72.

8. Dadej K, Bienias J. On fatigue stress-cycle curves of carbon, glass and hybrid carbon/glass-reinforced fibre metal laminates. Int $\mathrm{J}$ Fatigue. 2020;140:105843.

9. Liu Z, Curioni M, Jamshidi P, Walker A, Prengnell P, Thompson GE, Skeldon P. Electrochemical characteristics of a carbon fibre composite and the associated galvanic effects with aluminium alloys. Appl Surf Sci. 2014;314:233-40.

10. Peng Z, Nie X. Galvanic corrosion property of contacts between carbon fiber cloth materials and typical metal alloys in an aggressive environment. Surf Coat Technol. 2013;215:85-9.

11. Rajkumar GR, Krishn M, Narasimhamurthy HN, Keshavamurthy YC, Nataraj JR. Investigation of tensile and bending behavior of aluminum based hybrid fiber metal laminates. Procedia Mater Sci. 2014;5:60-8.

12. Surowska B, Ostapiuk M, Jakubczak P, Drozdziel M. The durability of an organic-inorganic sol-gel interlayer in Al-GFRP-CFRP laminates in a saline environment. Materials. 2019;12(15):2362.

13. Stoll MM, Weidenmann KA. Fatigue of fiber-metal-laminates with aluminum core, CFRP face sheets and elastomer interlayers (FMEL). Int J Fatigue. 2018;107:110-8. 
14. Adamos L, Tsokanas P, Loutas T. An experimental study of the interfacial fracture behavior of Titanium/CFRP adhesive joints under mode I and mode II fatigue. Int J Fatigue. 2020;136:105586.

15. Müller B, Hagenbeek M, Sinke J. Thermal cycling of (heated) fibre metal laminates. Compos Struct. 2016;152:106-16.

16. Park SY, Choi WJ, Choi HS. The effects of void contents on the long-term hygrothermal behaviors of glass/epoxy and GLARE laminates. Comp Struct. 2010;92:18-24.

17. Khosravani MR, Wienberg K. Experimental investigations of the environmental effects on stability and integrity of composite sandwich T-joints. Materialwissenschaft Werkstofftechnik. 2017;48:753-9.

18. García-Moreno I, Caminero MA, Rodríguez GP, López-Cela JJ. Effect of thermal ageing on the impact damage resistance and tolerance of carbon-fibre-reinforced epoxy laminates. Polymers. 2019;11:160.

19. Jakubczak P, Bienias J, Surowska B. Interlaminar shear strength of fibre metal laminates after thermal cycles. Compos Struct. 2018;206:876-87.

20. da Costa AA, da Silva DFNR, Travessa DN, Botelho EC. The effect of thermal cycles on the mechanical properties of fibermetal laminates. Mater Des. 2012;42:434-40.

21. Alam P, Mamalis D, Robert C, Floreani C, Brádaigh CMO. The fatigue of carbon fibre-reinforced plastics-a review. Compos Part B. 2019;166:555-79.

22. Zhou S, Li Y, Fu K, Wu X. Progressive fatigue damage modelling of fibre-reinforced composite based on fatigue master curves. Thin-Walled Struct. 2021;158:107173.

23. D'Amore A, Grassia L. A method to predict the fatigue life and the residual strength of composite materials subjected to variable amplitude (VA) loadings. Comp Struct. 2019;228:111338.

24. Alderliesten RC. Designing for damage tolerance in aerospace: a hybrid material technology. Mater Des. 2015;66:421-8.

25. Homan JJ. Fatigue initiation in fibre metal laminates. Int J Fatigue. 2006;28:366-74

26. Wang W, Rans C, Benedictus R. Analytical prediction model for non-symmetric fatigue crack growth in Fibre Metal Laminates. Int J Fatigue. 2017;103:546-56.

27. Wang W, Rans C, Zhang Z, Benedictus R. Prediction methodology for fatigue crack growth behaviour in Fibre Metal Laminates subjected to tension and pin loading. Compos Struct. 2017;182:176-82.

28. Meng W, Li Y, Zhang X, Zhang Y, Wang Y, Huang X. Analysis and prediction on total fatigue life problems of fiber reinforced metal laminates under two-stage loading. Compos Struct. 2020;237:111960.

29. Rans CD, Alderliesten RC, Benedictus R. Predicting the influence of temperature on fatigue crack propagation in Fibre Metal Laminates. Eng Fract Mech. 2011;78:2193-201.

30. EN ISO14130:1997. Fibre-reinforced plastic composites-determination of apparent interlaminar shear strength by short-beam method. Switzerland: InternationalOrganization for Standardization; 1997.

31. Hagenbeek M, Sinke J. Effect of long-term thermal cycling and moisture on heated Fibre Metal Laminates and glass-fibre epoxy composites. Compos Struct. 2019;210:500-8.
32. Li H, Hu Y, Liu C, Zheng X, Liu H, Tao J. The effect of thermal fatigue on the mechanical properties of the novel fiber metal laminates based on aluminum-lithium alloy. Compos Part A. 2016;84:36-42.

33. Zhong Y, Joshi SC. Response of hygrothermally aged GLARE 4A laminates under static and cyclic loadings. Mater Des. 2015;87:138-48.

34. Teixeira de Freitas S, Sinke J. Failure analysis of adhesivelybonded metal-skin-to-composite-stiffener: effect of temperature and cyclic loading. Compos Struct. 2017;166:27-37.

35. Botelho EC, Pardini LC, Rezende MC. Evaluation of hygrothermal effects on the shear properties of Carall composites. Mat Sci Eng A. 2007;452-453:292-301.

36. Ali A, Duan L, Zheng Z, Sapkota B. Characterization of seawater hydrothermal conditioning effects on the properties of titaniumbased fibre-metal laminates for marine applications. Compos Struct. 2016;158:199-207.

37. Choi HS, Ahn KJ, Nam J-D, Chun HJ. Hygroscopic aspects of epoxy/carbon fibre composite laminates in aircraft environments. Compos Part A. 2001;32:709-20.

38. Wang D, Bierwagen GP. Sol-gel coatings on metals for corrosion protection. Prog Org Coat. 2009;64:327-38.

39. Ebnesaijad S. Surface treatment of materials for adhesive bonding, 2nd edn. Amsterdam: William Andrew Elsevier; 2014. Chapter 7, pp. 139-83.

40. Bieniaś J, Jakubczak P, Droździel M, Surowska B. Interlaminar shear strength and failure analysis of aluminium-carbon laminates with a glass fiber interlayer after moisture absorption. Materials. 2020;13:2999.

41. Cui H, Koussios S, Li Y, Beukers A. Measurement of adhesive shear properties by short beam shear test based on higher order beam theory. Int J Adhes Adhes. 2013;40:19-30.

42. Hader-Kregl L, Wallner GM, Kralovec C, Eyßell C. Effect of inter-plies on the short beam shear delamination of steel/composite hybrid laminates. J Adhes. 2019;95(12):1088-100.

43. Calabrese C, Laird C. Cyclic stress-strain response of two-phase alloys part I. Microstructures containing particles penetrable by dislocations. Mater Sci Eng. 1974;13(2):141-57.

44. Kubit A, Trzepiecinski T, Kłonica M, Hebda M, Pytel M. The influence of temperature gradient thermal shock cycles on the interlaminar shear strength of fibre metal laminate composite determined by the short beam test. Compos Part B. 2019;176:107217.

45. Dadej K, Surowska B, Bieniaś J. Isostrain elastoplastic model for prediction of static strength and fatigue life of fiber metal laminates. Int J Fatigue. 2018;110:31-41.

Publisher's Note Springer Nature remains neutral with regard to jurisdictional claims in published maps and institutional affiliations. 